\title{
El iconismo gráfico en la escritura publicitaria ${ }^{1}$
}

Juan Rey

La cuestión fundamental de este trabajo puede plantearse de la siguiente manera: ¿Cómo la tipografía ayuda a subsanar, sortear, evitar algunos de los problemas derivados del empleo de un código tan complejo como el escrito? En otros términos: ¿Cómo el propio código escrito, a pesar de las dificultades que plantea, puede contribuir, en el caso concreto de la redacción publicitaria, a facilitar la comprensión del mensaje? Para responder a estas interrogantes es necesario aludir, aunque de forma somera, a los conceptos de código oral y código escrito y a los diferentes niveles de eficacia comunicativa que cada uno de ellos comporta, pues el hecho de que la comunicación se desarrolle en uno o en dos contextos da lugar no sólo a la aparición de dos códigos diversos con características diferentes (oral o escrito respectivamente), sino que también da lugar a la puesta en marcha de dos estrategias asimismo diferentes. $Y$ estas distintas características y estrategias están condicionadas por el contexto o los contextos en los que cada uno de ellos debe comunicar. La diferencia básica entre uno y otro código radica no tanto en la formalización del escrito o la espontaneidad del oral como en la distinta naturaleza en la que se apoya cada uno de ellos. El código verbal se basa en la oralidad. El escrito, en la visualidad.

1. La documentación gráfica de este trabajo ha sido realizada conjuntamente por el autor y Manuel Garrido Lora. 
Tradicionalmente se viene sosteniendo que la escritura es un código sustitutorio de la lengua sin más objetivo que fijarla. Sin embargo basta comparar la transcripción de una conversación oral con una carta para observar que tal identidad no existe. Los contextos son distintos, los elementos que intervienen en la comunicación también y por tanto estas diferencias se traducen en dos tipos de expresión distintos, aunque tienen algunos elementos en común (las letras pretenden representar los sonidos). El código verbal se fundamenta en lo oral y el escrito en lo visual. Y esta fundamentación diversa establece una nueva diferencia entre uno y otro código, ya que el escrito se materializa en unos trazos -las letras- cuyo aspecto visible, además del significado convencional, puede aportar un significado extralingüístico gracias a su capacidad figurativa, ya que va a ser precisamente en la sustancia -en la visualidad- en la que el código escrito publicitario va a basar toda su estrategia para sortear los problemas derivados del doble contexto en el que tiene que desempeñar su función.

La redacción está estrechamente ligada al código escrito. Por ello es fundamental la influencia de la tipografía en el discurso publicitario, discurso que, debido a la ruptura que históricamente se produce entre el productor y el consumidor, recurre a la escritura con el fin de establecer un puente que salve la distancia entre ambos. Por escritura hay que entender el conjunto de signos gráficos de carácter simbólico que, en las lenguas occidentales, se relacionan con una secuencia sonora concreta a la que se le atribuye un significado determinado. Se trata de un sistema de trazos formalizados y de carácter instrumental, cuya función es remitir convencionalmente a unos sonidos, que a su vez remiten arbitrariamente a un significado. Como puede observarse, la piedra angular sobre la que se apoya la comunicación escrita es la arbitrariedad, arbitrariedad que coincide con la del sistema verbal. Tanto el sistema oral como el gráfico envían a un referente con el que han cortado toda relación analógica y éste es mencionado mediante el flatus vocis en un caso y mediante unos trazos en otro, es decir, es referido mediante unos sonidos y unos signos gráficos que nada tienen que ver con él. Sin embargo en la redacción publicitaria no siempre ocurre así. 


\section{El suicidio lingüístico}

Además de la lengua, que es un sistema de comunicación basado en la ausencia de imitación y en la carencia de toda similitud con el mundo referido, el hombre ha creado otros sistemas de expresión basados en la analogía. Estos otros sistemas (imitativos e icónicos), gracias a los diversos soportes que usan (la forma, el color...), reifican los rasgos más sobresalientes del significado al que se refieren. Así puede verse en la pintura, la escultura... Sin embargo la lengua rechaza toda reproducción de la realidad y renuncia a las lisonjas de la mímesis sensorial. En palabras de Hagège, la lengua se ha suicidado. Y este suicidio le ha reportado grandes ventajas:

$1^{\circ}$ La ha liberado de la impregnación material a la que están sujetas la pintura o la escultura y las ha hecho abstracta.

$2^{\circ} \mathrm{Al}$ aludir al significado de forma arbitraria, ha reforzado su capacidad semántica.

$3^{\circ}$ Y todo ello le ha permitido crear un sistema de comunicación autónomo.

Sin embargo estas ventajas llevan aparejadas algún inconveniente. Frente a la capacidad de los lenguajes visuales, que pueden reproducir el mundo en casi toda su riqueza sensorial, la lengua es una pálida ilusión de la realidad que pretende reflejar, es un medio pobre y opaco que tiene que confiar a la imaginación del lector la recreación del referente al que alude (Block de Behar 1973: 190).

Lo mismo puede decirse de la escritura. Se trata de unos signos visibles, convencionales y funcionales. Unos trazos sin más cometido que representar unos sonidos. Pero esto tampoco fue históricamente así. Román Gubern, haciendo un rápido esbozo de la historia de la escritura (1987: 5659), establece tres periodos: el pictográfico, el logográfico y el fonográfico. Y en el paso del segundo al tercero sitúa el gran cisma histórico:

El salto cualitativo hacia el invento de la escritura fonética inauguró el gran cisma histórico entre cultura icónica (artes plásticas) y cultura literaria (de lettera, letra). Este cisma puede hacer olvidar fácilmente a nuestros contemporáneos que la matriz histórica de la escritura se halla en la expresión icónica, tronco común que la cultura griega iluminó al designar con la misma palabra (graphein) las actividades de dibujar, pintar y escribir. 
A partir de este momento, como dice Gubern, se produce un gran divorcio histórico que va a desembocar en dos culturas distintas y en dos formas diferentes de entender y representar la realidad. Este cisma da lugar a dos tipos de trazo:

-Un trazo icónico o imitativo, vinculado al mundo visual y perceptual, que es el origen de todos los modos de representación visual.

-Un trazo esquemático o abstracto, vinculado al mundo conceptual y mental, que es el origen de todos los códigos de representación conceptual (Costa 1988: 9).

Si bien no conviene olvidar que el trazo abstracto nace del trazo icónico, que se desgaja de él al renunciar a cualquier tipo de relación con el mundo perceptual y visual. De este modo, la escritura desemboca en una organización similar a la de la lengua. Y si en el plano de la expresión lingüística, según Hjelmslev, hay una forma (fonema) que se corresponde con una sustancia (sonido), otro tanto sucede en el terreno de la escritura: existe una forma (grafema) que se corresponde con una sustancia (alógrafo). El grafema es la invariante mientras que el alógrafo la variante. El primero es la representación mental de la letra y el segundo su ejecución concreta sobre el papel. Pero a diferencia de la lengua, en la que los sonidos remiten a un concepto, en la escritura los trazos no envían a ningún concepto sino que remiten a los sonidos que son los que aluden al concepto. Los signos gráficos carecen de significado propio y de contenido particular, porque los grafemas son las unidades mínimas de un sistema secundario que representan a los fonemas que son las unidades mínimas del sistema primario, que son las que remiten al referente. Sin embargo esto no siempre sucede así en la redacción publicitaria, ya que la publicidad juega con los alógrafos y explota las variantes con el fin de obtener nuevos significados.

\section{La vuelta a los orígenes: la doble vía}

A partir del cisma antes mencionado se establece un predominio del trazo esquemático. Este predominio se debe, en términos generales, a que las posibilidades técnicas de reproducción de la realidad eran escasas y rudi- 
mentarias. Cuando el desarrollo tecnológico permite reproducir analógicamente la realidad, estamos hablando del siglo XX, la relación entre ambos trazos cambia sensiblemente. Frente al trazo abstracto surge ahora el trazo icónico, mejorado, reforzado y ampliado por la técnica. Y no sólo surge sino que además intenta recuperar parte de su predominio perdido. En la actualidad, la capacidad de expresión desarrollada por los sistemas icónicos no ha arrinconado a la escritura, sin embargo en el ámbito de la publicidad le ha impuesto una reconsideración de su papel. Y esta reconsideración consiste en una búsqueda retrospectiva de sus orígenes. Las nuevas maneras de comunicar que han aparecido en la era moderna -basadas en la analogía- han incidido en el sistema gráfico estándar obligándolo a volver la mirada al pasado. La abstracción ha dotado a la escritura de grandes ventajas, pero la ha privado de la posibilidad de representar miméticamente la realidad. Y es hacia la escritura pictográfica hacia donde ahora dirige su mirada la escritura publicitaria.

En el sistema estándar, la escritura mantiene una relación de subordinación con la lengua, ya que se trata de unos trazos asépticos sin más fin que representar unos sonidos. En cambio en el sistema publicitario, la escritura, sin renunciar a su capacidad simbólica de representar la realidad, y dado que también es un trazo, procura y busca en su propia sustancia, en su materialidad, aquellos elementos que puedan pintar la realidad. La escritura publicitaria desanda por tanto un largo recorrido histórico para volver al punto en el que ambos trazos eran uno solo. Pero este regreso es imposible. O al menos la conjunción de los dos trazos ya no será igual que antes del divorcio, porque en ningún momento la escritura renuncia a su condición de signo arbitrario, sino que a su forma simbólica de representar la realidad le añade otra manera de aludir, esta vez icónicamente, al mismo contenido. En la escritura publicitaria conviven las dos formas de expresión y por tanto su percepción, como afirma Block de Behar, se realiza por una doble vía visual (1973: 199).

En el sistema publicitario, el signo gráfico se convierte en escritura y simultáneamente en pintura. La publicidad pretende que el trazo gráfico no sólo sea leído sino también visto, ya que, si en su calidad de escritura remite 
al concepto de manera lingüística, en su calidad de pintura puede aludir al mismo concepto por la vía figurativa. En este sentido la escritura publicitaria se acerca a la escritura pictográfica, sin embargo conviene recordar una vez más que en ningún momento la iconización publicitaria se desentiende del signo gráfico, sino que lo incorpora al iconismo y lo semantiza al dotarlo de un significado del que carece en la escritura estándar.

Después de una larga alfabetización, los signos gráficos se han transformado en meros instrumentos que desplazan mecánicamente la atención del lector hacia el contenido sin que éste repare en su existencia sensible. La escritura publicitaria rompe esta dinámica rutinaria y reclama la atención del lector hacia la forma sensible de la grafía, hacia su materialidad, de manera que el trazo publicitario se convierte en el punto de encuentro de dos formas distintas de expresión:

-Una: simbólica, lineal, analítica, abstracta y autónoma (Relacionada con la Pintura).

-Otra: icónica, global, sintética, figurativa y secundaria (Relacionada con la Escritura).

\section{Funciones del iconismo gráfico}

A pesar de la fuerte y progresiva alfabetización, el hombre no ha renunciado a la escritura pictográfica y a lo largo de los siglos en ningún momento ha dejado de conjugar el sistema gráfico y el pictográfico. Así puede observarse en los caligramas que recorren la historia de la literatura desde la Antigüedad hasta hoy. Ahora bien, las razones por las que la literatura y la publicidad acuden este recurso son distintas. En el discurso literario, por su propia naturaleza, predomina la función poética, función que en cierto modo se relaciona con el deseo de los artistas de superar los límites impuestos por las convenciones lingüísticas y gráficas (Bécquer hablaba del «mezquino idioma» y soñaba con «palabras que fuesen a un tiempo / suspiros y risas, colores y notas») . Casi lo mismo pretenden los publicitarios, aunque su finalidad es distinta. En el discurso publicitario la función poética es sólo el envoltorio, ya que para la publicidad el arte no es un fin en sí mismo, sino un recurso puesto 
al servicio de la persuasión del destinatario y la seducción del posible cliente. Esta subordinación se debe a que se trata de un discurso eminentemente apelativo. En líneas generales puede afirmarse que la publicidad explota el iconismo gráfico para desautomatizar la lectura, llamar la atención sobre el propio mensaje y sobresignificar la información, y todo ello con el fin de facilitar la comprensión del discurso publicitario y favorecer su memorización.

\subsection{Desautomatizar la lectura}

Desde una perspectiva científica se ha constatado que el lector medio apenas presta atención a los factores tipográficos debido a dos razones. La primera es que la lectura es un proceso fundamentalmente mental y lingüístico y muy secundariamente visual (Richaudeau 1987: 16). La segunda es que los signos gráficos, con el paso del tiempo, han perdido toda motivación y se han convertido en símbolos cuyo cometido es remitir indirecta y mecánicamente a un concepto. Mediante la iconización de la grafía, la publicidad obliga a la vista a detenerse en la materialidad de los signos, porque la palabra dibujada, al desviarse de la rutina gráfica, le ofrece al lector una nueva forma que no puede leer automáticamente, sino que con esa nueva disposición gráfica lo obliga a re-conocer los signos más que a verlos (Block de Behar 1973: 213).

Este reconocimiento deriva en un mayor interés de lectura y en un mayor esfuerzo de comprensión, que a su vez redundan en una mayor incidencia del mensaje en el lector, ya que para descodificarlo se ha visto obligado a sortear la automatización cotidiana. Pero además de esa detención en la pura forma sensible, la iconización significa también una ruptura de la linealidad del discurso (Sánchez Corral 1991: 80). A diferencia de la grafía, la imagen requiere una lectura global y este tipo de lectura se superpone a la lectura lineal del signo, surgiendo de este enfrentamiento una tensión que asimismo incide favorablemente en la recepción del mensaje, ya que ésta se lleva a cabo por una doble vía.

\subsection{Llamar la atención sobre el mensaje}

Gracias a la desautomatización, el mensaje deja de ser signo para con- 
vertirse en objeto, pero esta conversión no es gratuita como pudiera suceder en la literatura, sino que está motivada por la necesidad que tiene el discurso publicitario de hacerse visible y perceptible en un mercado en el que cada día es mayor la competencia no sólo comercial sino también visual (Dogana 1990: 375). La incesante aparición de mensajes publicitarios y su permanente coexistencia han dado lugar al nacimiento de un espacio muy contaminado visualmente. En medio de esta polución visual, el mensaje publicitario necesita reclamar la atención sobre sí mismo, necesita convertirse en un mensaje escandaloso a fin de destacar en medio del maremágnum visual en el que surge (Péninou 1976: 70). Y es esta necesidad de escándalo la que conduce a la publicidad a la utilización del iconismo gráfico como recurso para atraer la mirada del lector y para sobresalir en un ambiente cada vez más saturado visualmente.

\subsection{Sobresignificar la información}

En su empeño de destacar y captar la atención del destinatario, la publicidad siente la necesidad de ir más allá del mensaje lingüístico porque sabe que este mensaje es una convención gráfica que remite a la realidad mediante el espejismo semántico. Frente a otros sistemas de expresión, la lengua -en este caso la escritura- alude al referente a través del significado, pero este significado no es sino una pálida ilusión de referente. Mediante la iconización, la publicidad persigue un único objetivo: encarnar la ilusión semántica del signo lingüístico. La escritura pictográfica traduce figurativamente la misma idea que manifiesta la escritura fonográfica. De esta manera, la opacidad de los signos convencionales se vuelve transparente al reificar el concepto expresado en la materia perceptible (Block de Behar 1973: 190).

Esta semantización de la escritura sirve, pues, para expresar visualmente los mensajes. Gracias a este procedimiento semantizador, una misma información se transmite por una doble vía: una gráfica y otra pictográfica. Al reproducir la realidad a través de dos códigos, el iconismo convierte la escritura publicitaria en un sistema de expresión tautológico y redundante, ya que la información le llega al destinatario a través de las convenciones 
gráficas y al mismo tiempo se le ofrece a través de una representación analógica o parcialmente analógica del objeto representado, de modo que el receptor recibe dos impactos con el mismo mensaje: uno mental y otro visual. Tanto de esta sobresignificación como de la desautomatización y de la atención reclamada derivan las dos funciones siguientes.

\subsection{Facilitar la comprensión}

El doble impacto sirve para que el lector comprenda el mensaje más cómoda y fácilmente. A diferencia de la lectura gráfica, que, por muy automatizada que esté, exige el conocimiento de un código concreto y requiere cierto grado de atención, la lectura icónica no exige el conocimiento de ningún código específico, ya que se basa en la analogía del signo con lo representado y por lo tanto la comprensión es mucho más rápida al no mediar entre el referente y su expresión un signo arbitrario. Pero la mejor comprensión no sólo procede de esta similitud entre el icono y el referente, sino que también deriva de la doble vía por la que el destinatario accede al concepto, de la doble lectura que se le exige con este tipo de escritura y, por consiguiente, de la convergencia de los dos mensajes en una misma idea.

\subsection{Favorecer la memorización}

Desde antiguo es sabido que los lenguajes persuasivos lo primero que pretenden es hacerse recordables con el fin de causar el mayor impacto posible en el comportamiento del receptor. La publicidad como discurso seductor no es ajena a este comportamiento y busca en la iconización una forma de memorabilidad que la distinga de los demás (Dogana 1990: 39). El empleo del iconismo gráfico es un viejo recurso publicitario, sin embargo su empleo se ha acentuado en los últimos tiempos debido a los derroteros tomados por la sociedad de consumo. El desarrollo tecnológico ha propiciado prácticamente la desaparición de diferencias reales entre los diversos productos que la publicidad oferta al consumidor. Ante la imposibilidad distinguirlos por sus características técnicas, prácticas o funcionales, la publicidad opta entonces por desplazar la atención de los rasgos denotati- 
vos a los connotativos, de los motivos racionales a los irracionales y busca caracterizar el producto no con argumentos lógicos sino mediante la seducción de las imágenes, las sensaciones y las emociones (Dogana 1990: 373).

$\mathrm{Y}$ es en este momento cuando entra en juego el iconismo gráfico, ya que el mensaje contribuye a la caracterización del producto al convertirse él mismo en expresión de las características del producto del que habla. El iconismo publicitario, en su calidad de pintura, se convierte en un excelente signo mnemotécnico, en un estímulo asociativo e inductivo que se incorpora a los esquemas mentales. El mensaje iconizado, gracias a la desautomatización, la confluencia de los dos códigos y sobre todo al impacto psicológico de la pictografía, se convierte en un signo memorizante y a ello contribuyen también los siguientes factores: 1) La originalidad, que le otorgan la personalidad y la diferenciación, 2) El valor simbólico, que lo inscribe en el universo emocional, 3) La novedad formal, que lo dota de un mayor poder de impacto, y 4) La cualidad estética, que le proporciona fascinación y seducción (Costa 1989: 64).

\section{Iconismo gráfico y escritura publicitaria}

El desmesurado afán de equiparar analógicamente el signo con el referente lleva al discurso publicitario a aplicar el iconismo a todos los niveles linguísticos. Sin embargo es en el terreno de la grafía en el que este recurso es más frecuente y en el que asimismo la publicidad ha aportado una mayor innovación y creatividad. Esta frecuencia se debe a dos factores. Primero, a las posibilidades pictóricas que ofrece la grafía frente a la fonética o la morfosintaxis, basadas en la oralidad y no en la pintura como le sucede a la escritura. Y segundo, a la capacidad que tiene la grafía de imponerse en la percepción y en la memorización (Dogana 1991: 25).

Ahora bien, la iconización del signo publicitario no siempre se lleva a cabo de idéntica manera. En el proceso de analogización de la forma puede establecerse una gradación que va desde los aspectos más externos de la grafía hasta la total transformación de las letras en un dibujo. Es 
decir, este proceso parte de un primer nivel gráfico, le sucede otro en el que el sistema gráfico convive con el pictográfico, y finalmente el pictográfico invade todo el mensaje.

\subsection{Nivel gráfico}

En este primer momento la publicidad recurre sóló al código escrito estándar para expresar el concepto. Sin embargo este código no permanece intacto, sino que sufre ligeras modificaciones que, aunque no alteran su carácter de trazo abstracto, tienen la función de reproducir algunos de los rasgos más sobresalientes del referente. La representación de la realidad se busca a través de un uso especial de los recursos puramente gráficos, elementos que, si en la escritura convencional pasan desapercibidos a los ojos del lector, ahora cobran vida y van más allá de su mero uso funcional. Estos recursos son, por una parte, la componente gráfica (constituida por el tamaño del tipo, el peso, el diseño, el color, el contraste y la horizontalidad) y, de otra, por los propios signos (que pueden repetirse o permutarse).

\subsubsection{Tamaño del tipo}

Recurriendo al tamaño de los tipos se pueden manifestar algunos de los rasgos más sobresalientes del concepto expresado. Así sucede en una inserción de los ordenadores Vectra VL2 de Hewlett Packard en la que la palabra Reduce va menguando su tamaño paulatinamente. Mediante un sabio empleo del tamaño, en un anuncio de Schweppes se indican las diversas posibilidades de combinar la bebida y al mismo tiempo se expresa la excelencia de los combinados en términos ingleses: gIN, rON, $O d K a$. También la publicidad institucional recurre al iconismo gráfico. En la campaña llevada a cabo por la Fundación de Ayuda contra la Drogadicción, mientras que las sucesivas invitaciones al consumo de la droga aparecen en un tamaño pequeño, la respuesta negativa del joven tentado se expresa con un cuerpo mayor y un peso mayor, rasgos gráficos que vienen a traducir la contundencia y la vehemencia de la negación, contundencia y vehemencia que se acentúan cuando, en otra inserción, el No ocupa toda la página (Véase figura 1). 


\subsubsection{Peso del tipo}

$\mathrm{Al}$ margen de los problemas de legibilidad relacionados con la pesadez o ligereza de los tipos empleados, el peso también sirve para reproducir algunos de los rasgos formales del referente. En el logotipo Crescendo la idea de aumento progresivo se expresa mediante el paso gradual de un tipo ligerísimo, que apenas contrasta con el fondo, a otro más pesado. Lo mismo sucede con los preservativos Contatto $^{2}$, en cuya inserción la noción de sutileza se traduce escribiendo el término sutil (sottile) con un trazo más delgado que el resto del texto (Véase figura 1).

\subsubsection{Diseño del tipo}

Como punto de partida puede admitirse que las formas del lenguaje escrito son formas relativamente estereotipadas y que mediante sus trazos no aluden a otra cosa que al sonido con el que la lengua oral se refiere al mundo circundante. Sin embargo esta apreciación inicial se ve parcialmente modificada cuando se observa que la grafía, sin abandonar los tipos normalizados, es también portadora de ciertos valores emocionales y psicológicos. A través de su diseño, los tipos estandarizados pueden expresar periodos históricos, estilos de vida, estados de ánimo, cualidades físicas... (Perfect 1994: 202). La modernidad, la elegancia, la fantasía, el arcaísmo o la robustez pueden expresarse sin recurrir a la iconización de la grafía, sólo eligiendo un tipo cuyo diseño evoque dichas cualidades. Y ello es posible porque los caracteres tipográficos, sólo a partir de su forma, son capaces de incidir en la emotividad del lector y proporcionarle una información suplementaria, una información que no deriva directamente del concepto expresado, aunque esté relacionada con él, sino del valor añadido del tipo seleccionado.

Pero en el mundo del grafismo, además de la escritura normalizada o industrial también existe la escritura libre o manual (Costa 1992: 126-

2. Tanto este ejemplo como los de Moby Prince, Frigoverre, Dianex, Eclipse y Tegostil, que aparecen en las figuras 5 y 6 , están tomados del libro de Fernando Dogana (1990). 
131). En la industrial prima la funcionalidad en detrimento de ulteriores significaciones, si bien, como se acaba de ver, tampoco la normalizada está libre de asociaciones culturales. En cambio la manual sacrifica la funcionalidad en beneficio de otros posibles significados. Frente a los trazos impersonales y fríos de la estandarizada, los de la manual resultan cálidos, íntimos, personales... Y la publicidad lo sabe y por ello recurre a la escritura manuscrita para expresar la opinión del consumidor que así se ve reflejado en el mensaje. Cuando el discurso publicitario le cede la palabra al cliente, recurre a la grafía manual. Así puede observarse en la inserción de los seguros de Cajamadrid en la que el usuario habla -escribe de su puño y letra- acerca de las bondades del servicio. Dentro de este tipo de escritura un trazo muy frecuente es el infantil. Como sucede en el anuncio del Peugeot 806 , con la desgarbada escritura escolar se le otorga al producto un aura de ingenuidad, inocencia, autenticidad y por supuesto de bondad (Véase figura 2).

\subsubsection{Color del tipo}

Aunque desde una perspectiva científica los colores carecen de significación, sí poseen, en cambio, por razones culturales y antropológicas una serie características asociativas adquiridas a lo largo de los siglos: el blanco indica la pureza, el rojo la pasión, el azul el frío... Estas asociaciones simbólicas son explotadas por la publicidad, en la que los envoltorios de los productos de limpieza e higiene personal, por ejemplo, suelen ser verdes o azules, porque el verde, al asociarse a la vegetación, evoca salud y bienestar y el azul, al relacionarse con el agua, sugiere higiene y limpieza. Algo similar viene a suceder con los productos infantiles, en los que predominan los colores pastel y los tonos cremas (March 1994³ 36 ).

Pero además de los diferentes significados que pueda tener por motivos culturales, el color también sirve para reproducir algún aspecto del objeto referido o resaltar unas letras frente a otras con el fin de ofrecer significados simultáneos. Así, la eficacia de los purificadores de aire Philips se manifiesta haciendo desaparecer poco a poco el color de las letras hasta dejarlas en blanco, es decir, puras (Véase figura 2). En el anuncio realiza- 
do por Saatchi \& Saatchi para la British Airways, cuyo eslogan es «Amsterdam-Belfast direct», la última sílaba de cada una de las ciudades aparece en otro color: Amsterdam y Belfast. Y gracias a este coloreado diverso, además de los puntos de origen y destino del vuelo, puede también leerse dam $(n)$ y fast, que en inglés significan respectivamente «endemoniadamente» $y$ «deprisa». Y en otra inserción de la cadena Cope, aparecida con motivo de las primeras elecciones libres en Suráfrica tras la desaparición del apartheid, se combina el blanco y el negro, obviamente remitiendo al enfrentamiento étnico en el país surafricano (Véase figura 3).

\subsubsection{Contraste}

Un aspecto directamente relacionado con el color es el contraste. Y también del contraste saca partido la escritura icónica. En un anuncio de los televisores Supertrinitron la excelente nitidez de su imágenes se manifiesta escribiendo la marca del producto con un trazo bien perfilado frente al resto del texto que está escrito con caracteres borrosos y poco nítidos. Dentro del contraste habría que incluir el icono de la velocidad, un recurso típico del cómic mediante el cual se indica el vertiginoso desplazamiento de los sujetos y de los objetos, y, en el caso de la publicidad impresa, de las letras que a su vez remiten al vertiginoso desplazamiento del referente. En un anuncio de Renfe, el texto dice « ¿Volar hasta Cádiz y Huelva en Talgo?», y sobre las letras aparecen unos trazos que, eliminando parcialmente el contraste entre los tipos y el fondo, indican la rapidez del servicio ferroviario (Véase figura 3).

\subsubsection{Horizontalidad}

A diferencia de otros sistemas de escritura, en el latino los signos se escriben horizontalmente de izquierda a derecha. También la publicidad obtiene partido de esta convención y son muchos los mensajes en los que el texto altera su horizontalidad gráfica para aludir al referente. Cuando la casa Sony lanza al mercado su lector de discos compactos, el título de la inserción es «Ni un terremoto hace temblar su voz» $\mathrm{y}$, mientras que todo el texto 
se mantiene nivelado, las letras de la palabra terremoto aparecen desequilibradas, reproduciendo así los efectos del seísmo. La apertura, después de la Exposición Universal de 1992, del Parque de la Cartuja se anuncia con el siguiente texto: «El parque se mueve». Y el movimiento se indica simultáneamente por la ondulación gráfica de «se mueve» (Véase figura 4).

\subsubsection{Onomatopeyas y metagrafos}

En última instancia, la publicidad, además de jugar con los elementos que configuran los signos gráficos, también juega con los propios signos: los repite o los sustituye con el fin de generar un significado que vaya más allá del estrictamente lingüístico. Para actuar sobre la escritura sin salir del sistema gráfico convencional la publicidad cuenta con la onomatopeya (reiteración) y el metagrafo (alteración).

La onomatopeya es un recurso que consiste en la repetición de una misma letra con el fin de imitar la prolongación del sonido en algunas situaciones. Así, cuando Pepsi patrocina la temporada de ópera de Palma de Mallorca bajo el eslogan de «Locos por la ópera», no tiene inconveniente en que su marca se transforme en Peeeeeeeeeeepsi, imitando quizás un do sostenido de José Carrera. O que en un anuncio de Bacardi \& Coca-Cola el título sea «Chisssspeante compañía», donde la reiteración de la $S$ remite al burbujeo y al chisporroteo de la refrescante bebida.

El metagrafo, en cambio, es un recurso que consiste en la sustitución de una letra por otra que representa idéntico sonido: «Sony es supersonyco». Este cambio no supone alteración alguna del significado originario de la palabra, pero, gracias a esta leve modificación, le añade nuevos significados y nuevas sugerencias a un signo estandarizado y vacío de contenido: «Hay frutas freskas con Kas». En un anuncio, el logotipo de Volkswagen (un círculo que contiene una $\mathrm{V}$ y una $\mathrm{W}$ superpuestas) sustituye al símbolo del oxígeno en la fórmula del agua $\left(\mathrm{H}_{2} \mathrm{O}\right)$, de manera que esta casa automovilística, con un simple trazo, expresa su adhesión al movimiento ecologista (Véase figura 5). Un gran metagrafo es un cartel contra la invasión de Afganistán en el que el nombre de este país figura siete veces. La primera vez aparece escrito con caracteres latinos, pero, a medida que se repite, los caracteres 
latinos van siendo sustituidos por los cirílicos hasta que la palabra termina toda escrita con esta última grafía. De esta manera la conquista de un país se manifiesta sólo por la metagrafía que domina todo el cartel (Véase figura 4).

\subsection{Nivel gráfico y pictográfico}

En su afán de reflejar la realidad, el discurso publicitario da un paso más y al sistema gráfico convencional le yuxtapone el pictográfico. Ahora, el referente es expresado mediante un doble código: la escritura y la pintura, sin embargo entre ellos no se produce una fusión que difumine sus fronteras, sino que cada uno conserva su autonomía e independencia frente al otro. Ambos códigos se limitan a convivir y a aportar cada uno su significado de forma tal que su convergencia significativa da lugar a un mensaje redundante. Esta combinación de los dos sistemas expresivos abarca desde los más elementales signos de puntuación hasta ocupar toda la palabra.

\subsubsection{En la periferia de la palabra}

El proceso de semantización del código gráfico se inicia con la iconización de los elementos más simples de la escritura: puntos, tildes... Y la relación que se establece entre estos signos iconizados y el referente es de la más diversa índole. En un viejo anuncio, la tilde de la palabra café se sustituye por un grano de café (relación analógica). En el logotipo de una empresa dedicada al transporte de motos llamada Tiburón la tilde es reemplazada por la aleta de un escualo (relación metonímica). En Frigoverre el punto de la $I$ ha sido sustituido por una estrella de nieve (relación simbólica) y en Dianex, un producto de limpieza doméstica, por una estrella reluciente (relación de causa-efecto) (Véase figura 5).

\subsubsection{Una letra}

La iconización se acentúa y, abandonando la periferia de la palabra, pasa a ocupar una letra, de forma tal que el sistema pictográfico se introduce en el interior del gráfico con cuyos signos convive. Ambos sistemas se yuxtaponen, pero conservan su autonomía expresiva. Este es el recurso icónico más frecuente en el discurso publicitario. Basta abrir un periódico o desplegar un 
folleto para encontrar una palabra en la que una de las letras ha sido sustituida por una imagen. Y esta sustitución da lugar a dos tipos de expresión.

Primero: la imagen que sustituye a la letra alude al mismo significado que la palabra en la que se incardina, de modo que tanto el código gráfico como el pictográfico vienen a decir lo mismo. En Saturno, una promotora de ocio y turismo, la $O$ es reemplazada por el planeta de los anillos casi verticales. En Eclipse, un vidrio de uso arquitectónico para reflejar la luz solar, la $C$ representa la luna tapada casi enteramente por el sol y el eclipse incluso oculta parte de la $L$ contigua (Véase figura 6).

Segundo: la imagen alude no a la palabra en la que se inserta sino al producto publicitado. En el VIP de Perrier, la $I$ es reemplazada por un botellín de agua mineral de la casa anunciada. Y en el título de un anuncio de Hilo Musical, varias letras $(Q, I$ y $S)$ han sido sustituidas por otros tantos instrumentos musicales -una guitarra, un oboe y un saxofón respectivamente- (Véase figura 6).

Este tipo de iconismo es muy común en la publicidad turística. Son muchos los reclamos en los que figura el nombre de la ciudad y una de las letras ha sido reemplazada metonímicamente por el monumento más significativo o el símbolo de la ciudad. De esta manera, la $A$ de Amsterdam y la $R$ de Canarias han sido sustituidas por la fachada de uno de los edificios típicos de la ciudad holandesa y por la flor del paraíso, símbolo adoptado por el Cabildo insular para la promoción turística de las islas (Véase figura 6).

\subsubsection{La palabra}

El iconismo gráfico, una vez superado el ámbito marginal e implantado en una letra, continúa su invasión y se expande ahora por toda la palabra. Se trata de ligeras modificaciones que hacen que la escritura exprese parcialmente a través de su forma, que en ningún momento deja de ser o parecer código escrito, algún rasgo del referente. Así, en el logotipo de las piscinas Jean Desjoyaux, la parte superior de las letras, escritas además en azul, parecen formar olas. Otro tanto puede observarse en Tegostil, una empresa dedicada a la fabricación de tejas, cuyo borde superior está diseñado de forma tal que los diversos trazos de la escritura semejan un tejado 
(Véase figura 6). Pero tanto en un caso como en otro se trata siempre de la convivencia de dos códigos que se respetan mutuamente: el gráfico, que no renuncia a su forma, y el pictográfico, que se le superpone.

\subsection{Nivel pictográfico}

El grado máximo de iconización de la escritura está constituido por los caligramas. En este caso, los dos códigos no conviven ni se yuxtaponen, sino que se fusionan dando lugar a un único mensaje, que, al poder descifrarse tanto a través del código escrito como del figurativo, se convierte en un mensaje total en el que la arbitrariedad del signo lingüístico (tanto oral como escrita) es negada por la reificación icónica del significado a través de los trazos gráficos que, si aisladamente no abandonan del todo su carácter convencional, globalmente se transforman en trazos pictográficos que dibujan el referente. El caligrama es una unidad visual compuesta por un mensaje linguírstico y otro icónico en la que ambos códigos se con-funden y conviven en una simbiosis en la que la imagen recubre y sustenta a la escritura.

Ahora, el código icónico no sólo invade la palabra sino que altera la escritura convencional, de manera tal que el código gráfico queda sometido y subordinado al pictográfico, ya que lo primero que percibe el lector es una forma -una pictografía- mediante la cual se alude al referente. El caligrama niega y destruye la linealidad de la escritura al convertirla en pintura. Este tipo de iconización máxima pretende una representación visual del significado y esta representación (más esquemática y convencional que analógica o figurativa) es la que condiciona la mirada y por tanto la que guía la lectura obligando al lector, primero, a percibir una imagen $y$, luego, a descifrar la escritura contenida en esa imagen (Dogana 1990: 52-61).

Este doble sistema de expresión, al negar la arbitrariedad y la linealidad del signo convencional, no sólo imposibilita la automatización de la lectura sino que además -y sobre todo- atrae la atención del lector de una manera inusitada. Y a ello se debe su gran empleo en la lengua publicitaria, a su capacidad para captar el interés del destinatario por encima de otros mensajes. Sin embargo conviene recordar que este recurso no es nuevo, sino 
que su presencia se constata a lo largo de la historia de la literatura, desde los poetas alejandrinos del siglo IV a.C. (Simias de Rodas, Calímaco, Teócrito) hasta la actualidad (Poesía visual, Concretismo), pasando por los autores latinos (Porfirio, Ausonio), los medievales (Alcuino de York, Teodulfo), los renacentistas (Rabelais) y los vanguardistas (Apollinaire, Huidobro). Esta realizaciones europeas, aisladas y esporádicas en el contexto general de su literatura, adquieren gran relevancia en la cultura árabe, en la que, al estar prohibida la representación analógica de la realidad, la escritura se convierte en el único vehículo para expresar el mundo y los signos gráficos abandonan su carácter convencional para transformarse en dibujos (Cózar 1991).

Esta técnica mixta, cuyo origen algunos relacionan con la cábala y la función mágica de la escritura, ha desbordado en la actualidad el marco de la literatura y se ha convertido en uno de los sistemas de expresión preferido del discurso publicitario. En la sociedad de consumo los caligramas han dejado de ser el divertimento de una élite o la expresión de una minoría y se han transformado en un medio masivo de comunicación, en un recurso cada vez más explotado. Raro es el diario o la revista en cuyas páginas no aparece un ejemplo, por mínimo que sea, de este iconismo. Y se ha hecho tan común su presencia en la publicidad que ha llegado a identificarse con la escritura publicitaria (Block de Behar, Calabrese, Pignotti y Sánchez Corral entre otros).

Los ejemplos de caligramas publicitarios son muchos (Véanse figuras 7 y 8). Basten, a título de muestra, los siguientes. Serpeska, una empresa de distribución de pescado, compone con su logotipo la figura de un pez. Otro tanto hace $E l$ Mundo, que con las letras dibuja un globo terráqueo, símbolo del diario. En un anuncio de Navidad, la casa Tupperware felicita a sus distribuidores y el texto de la felicitación se transforma en un abeto navideño. Onda Cero, con el texto del anuncio de la retransmisión de la Vuelta Ciclista a España, dibuja el sinuoso itinerario de una etapa. Casi lo mismo viene suceder en el cartel de la Semana Internacional de la Moda: La escritura se transforma en el hilo que ensarta una aguja. El texto de Klorane, una loción desmaquillante de ojos, dibuja el contorno de unos 
ojos. Las letras del modelo Midnight de la casa Peugeot se transforman en un perfil de rascacielos. Otro tanto sucede con el catálogo de SpringSummer 88, en el que las letras dibujan el sol, las gaviotas, las olas y los veleros de un paisaje marino. Coca-Cola basó su campaña de 1995 en el caligrama e inundó las vallas y lo autobuses con la silueta de su características botella, silueta que unas veces está formada por la palabra «Bébeme» y otra por «Refrescante» $\mathrm{o} «$ Glug, glug, glug». También la publicidad política o institucional recurre al caligrama para hacer más efectivos sus mensajes. Y así, Amnistía Internacional dibuja con su mensaje una vela encendida rodeada por una alambrada (su símbolo). Pero no sólo la publicidad impresa acude al iconismo gráfico. También la audiovisual, en tanto en cuanto sus mensajes también son visibles, recurre al iconismo gráfico. Baste recordar los numerosos espots televisivos en los que el código gráfico y el icónico se funden y confunden.

Como conclusión a cuanto se ha dicho anteriormente, puede afirmarse que la escritura publicitaria, acudiendo a la materialidad del código gráfico, recurriendo a los aspectos formales de la escritura y explotando los aspectos visuales de la grafía, contribuye a facilitar la comprensión del mensaje al aludir al referente mediante dos sistemas de comunicación distintos y complementarios. Es decir, gracias a la convergencia de dos códigos diversos, la redacción publicitaria establece una información redundante que -parcialmente- subsana las dificultades derivadas de un tipo de comunicación que, por su propia naturaleza, se desarrolla en un doble contexto. 


\section{REFERENCIAS BIBLIOGRÁFICAS}

BLOCK DE BEHAR, L. (1973): El lenguaje de la publicidad, Buenos Aires, Siglo XXI.

COSTA, J. (1988): Foto-diseño, Barcelona, CEAC. (1989): Imagen global, Barcelona, CEAC.

(1992): Identidad corporativa y estrategia de empresa, Barcelona, CEAC.

CÓZAR, R. (1991): Poesía e imagen. Formas dificiles del ingenio literario, Sevilla, El Carro de la Nieve.

DOGANA, F. (1990): Le parole dell'incanto, Milano, Franco Angeli. (1991): «Iconismi verbali nel linguaggio della pubblicità», en VV.AA.: Il linguaggio della pubblicità, Milano, Mursia, pp. 23-41.

GUBERN, R. (1987): La mirada opulenta, Barcelona, Gustavo Gili.

MARCH, M. $\left(1994^{3}\right)$ : Tipografia creativa, Barcelona, Gustavo Gili (Creative typography, London, Quarto Publishing, 1988).

PÉNINOU, G. (1976): Semiótica de la publicidad, Barcelona, Gustavo Gili (Intelligence de la publicitè: Étude sémiotique, Paris, Robert Laffont, 1972).

PERFECT, C. (1994): Guía completa de la tipografia, Barcelona, Blume (The complete typographer, London, Quarto Publishing, 1992).

RICHAUDEAU, F. (1987): La legibilidad: Investigaciones actuales, Madrid, Fundación Germán Sánchez Ruipérez (La lisibilité. Recherches actuelles, Paris, Editions Retz, 1984).

SÁNCHEZ CORRAL, L. (1991): Retórica y sintaxis de la publicidad (Itinerarios de la persuasión), Córdoba, Servicio de Publicaciones de la Universidad de Córdoba. 

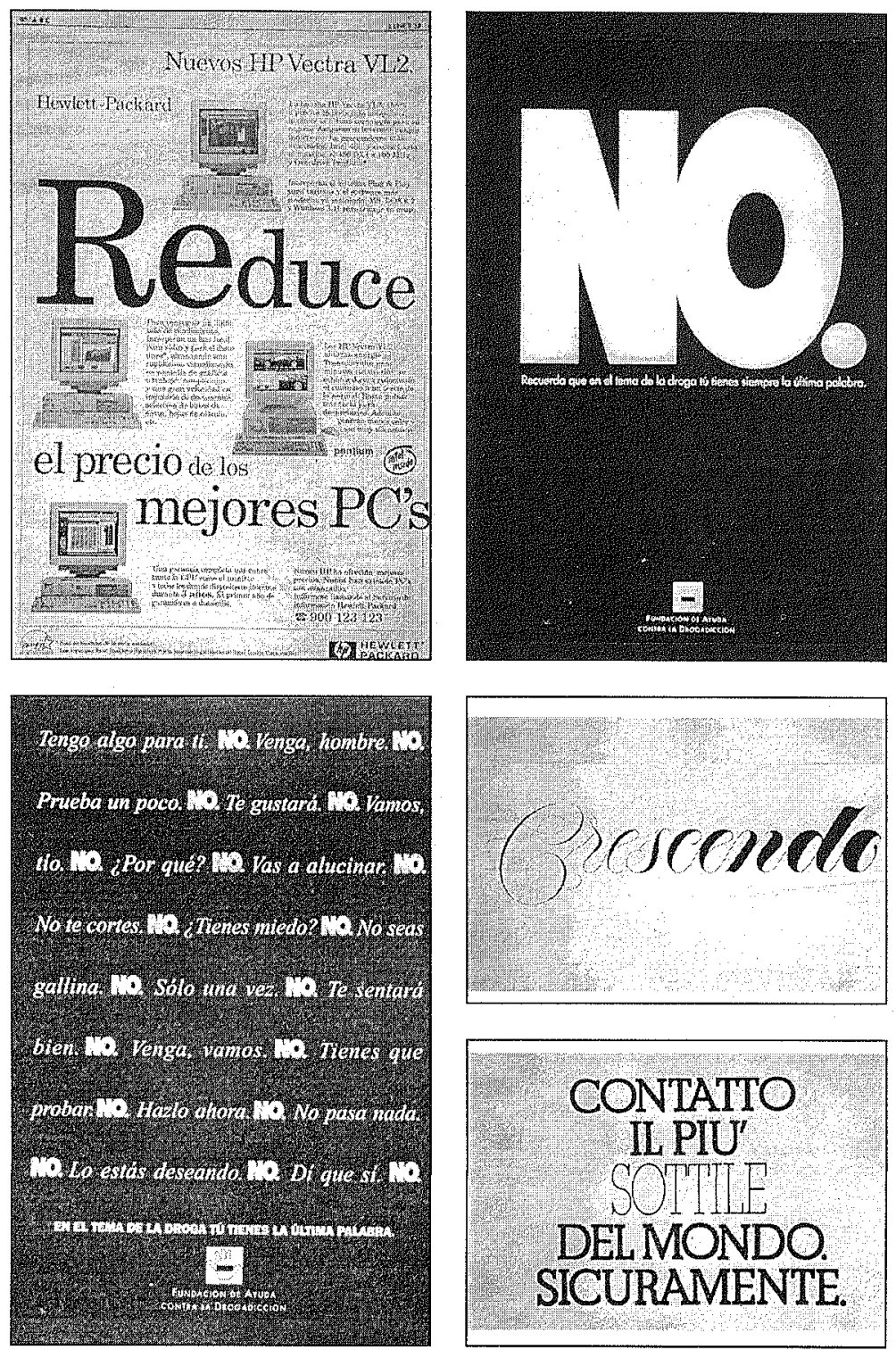

Figura 1 

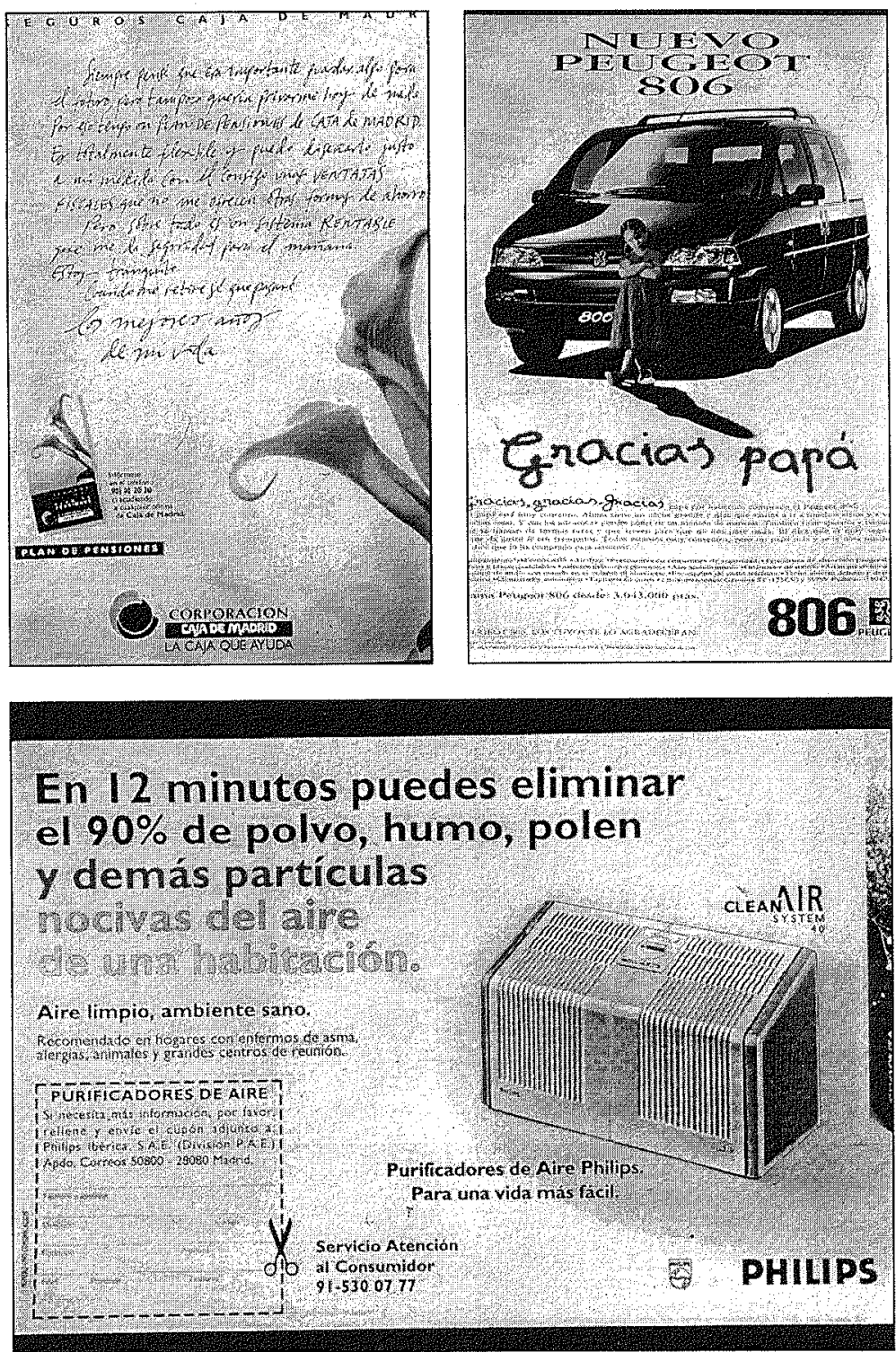

Figura 2 


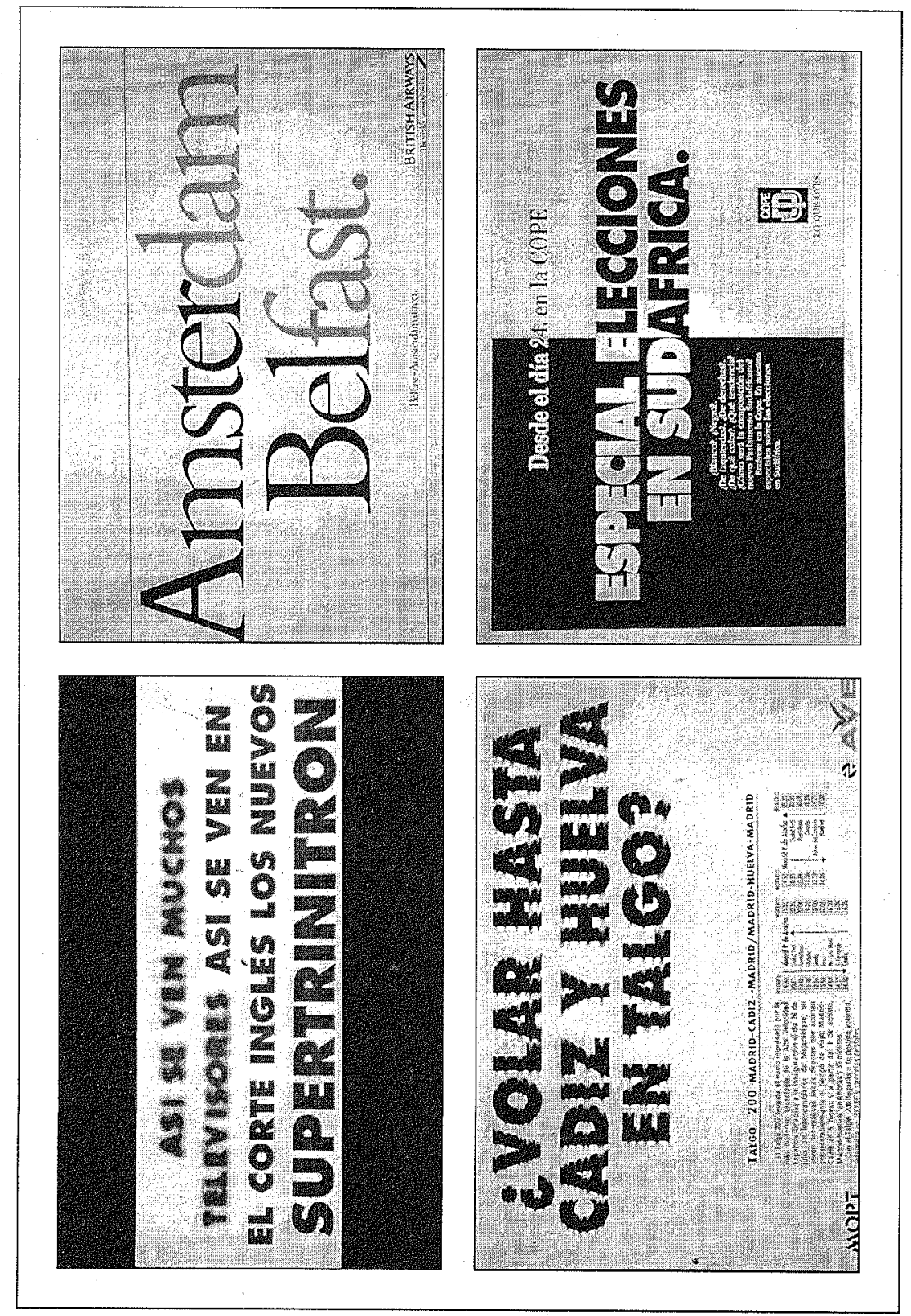

Figura 3 

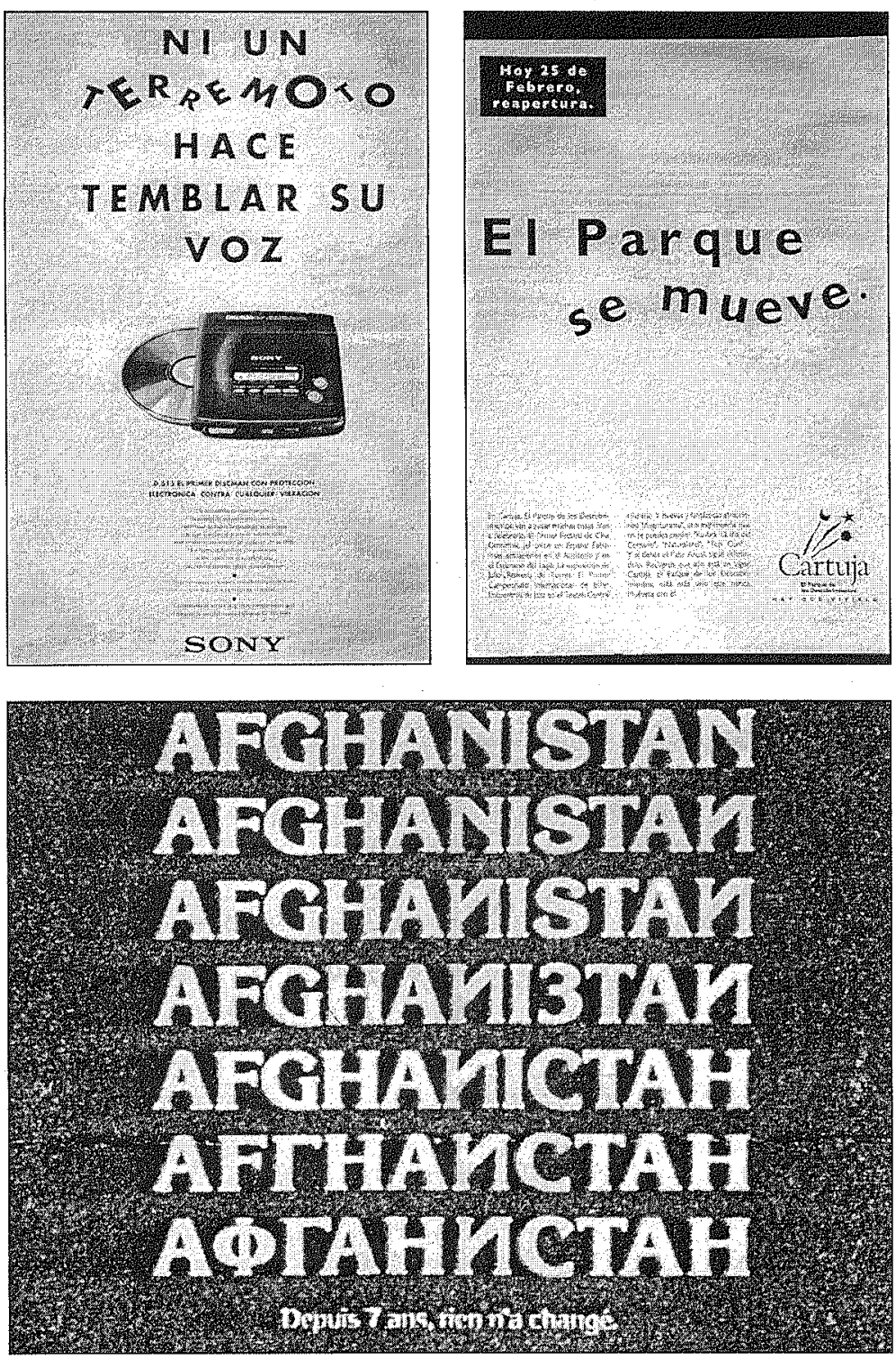

Figura 4 


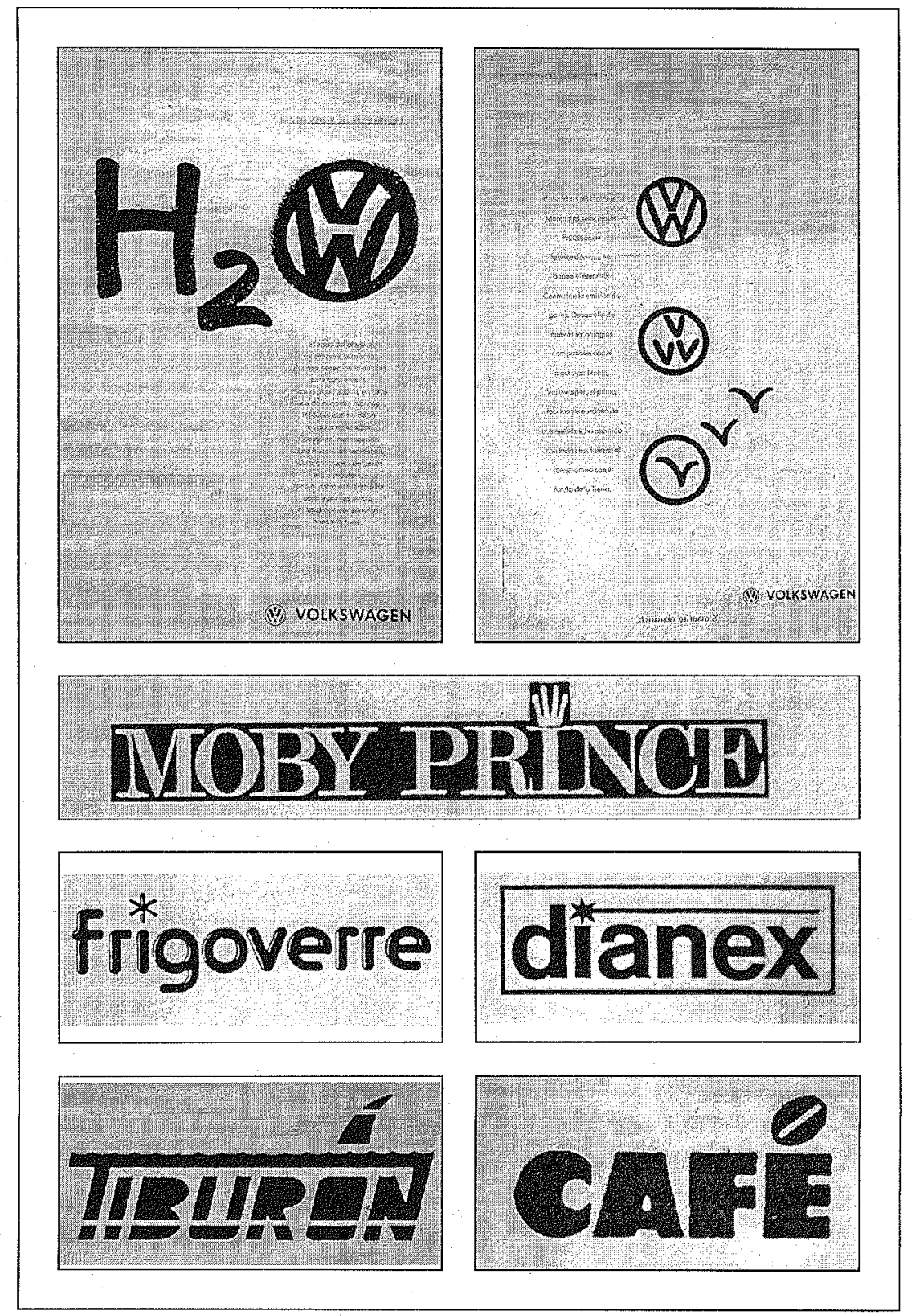

Figura 5 

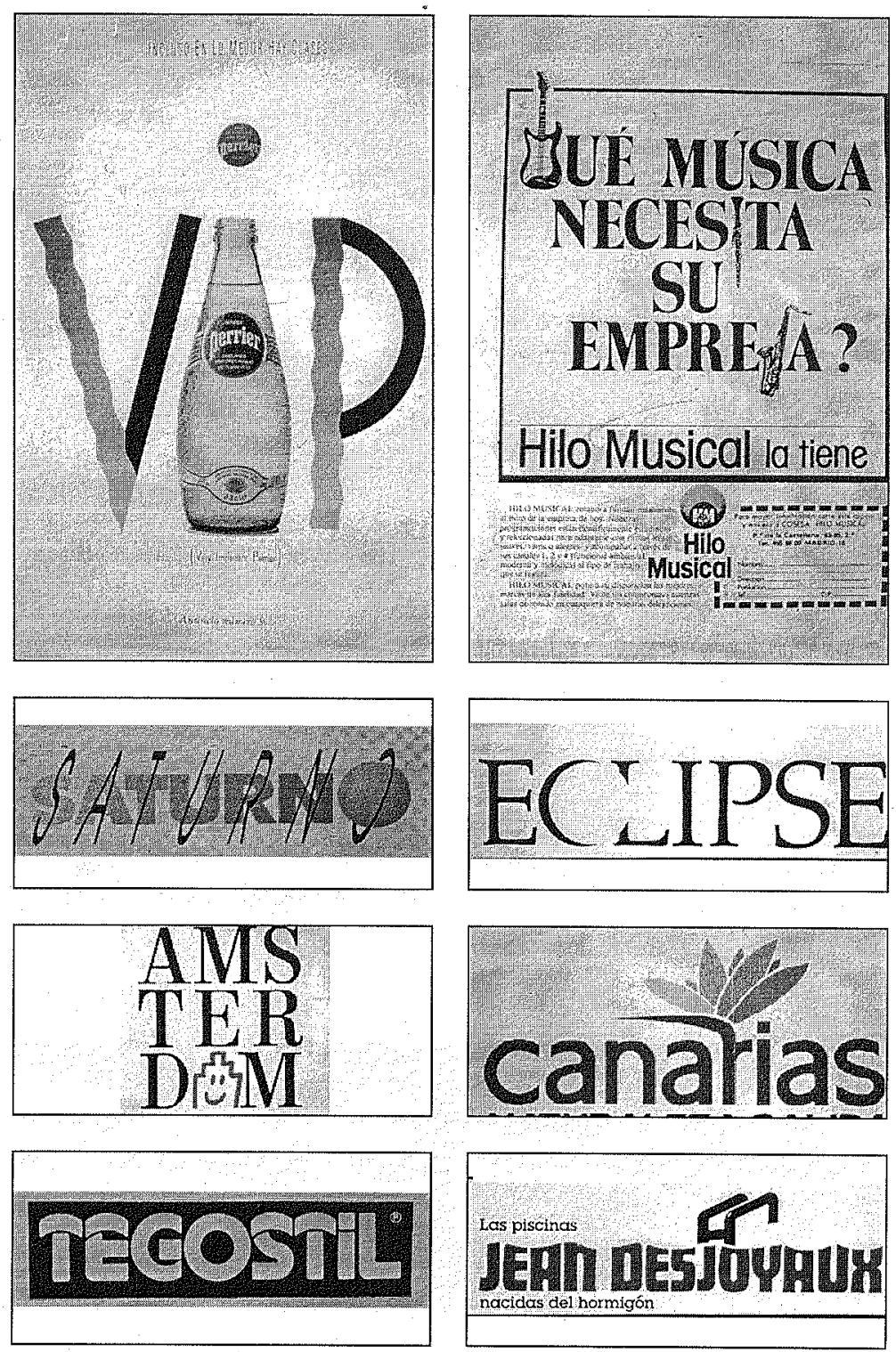

Figura 6 


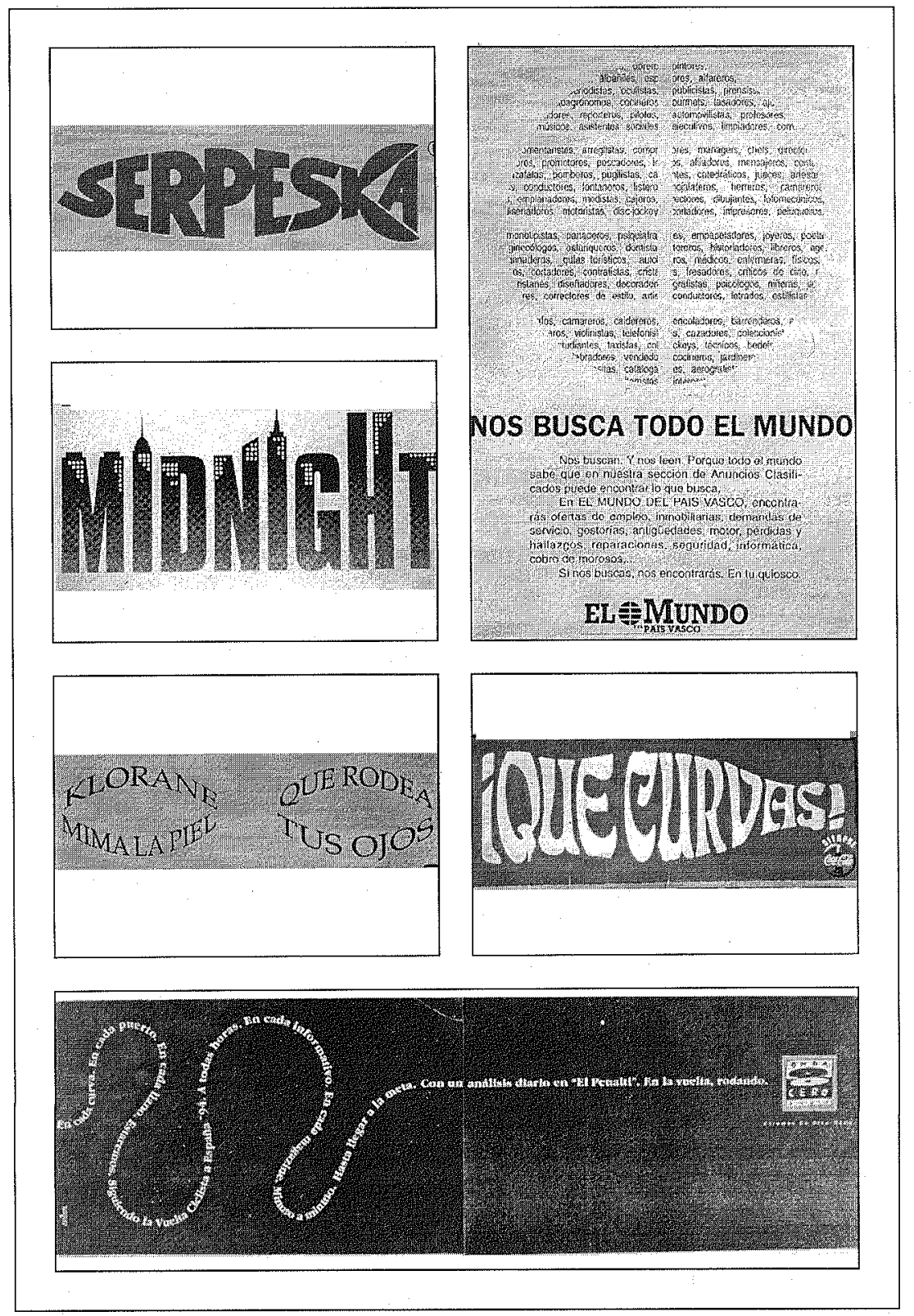

Figura 7 

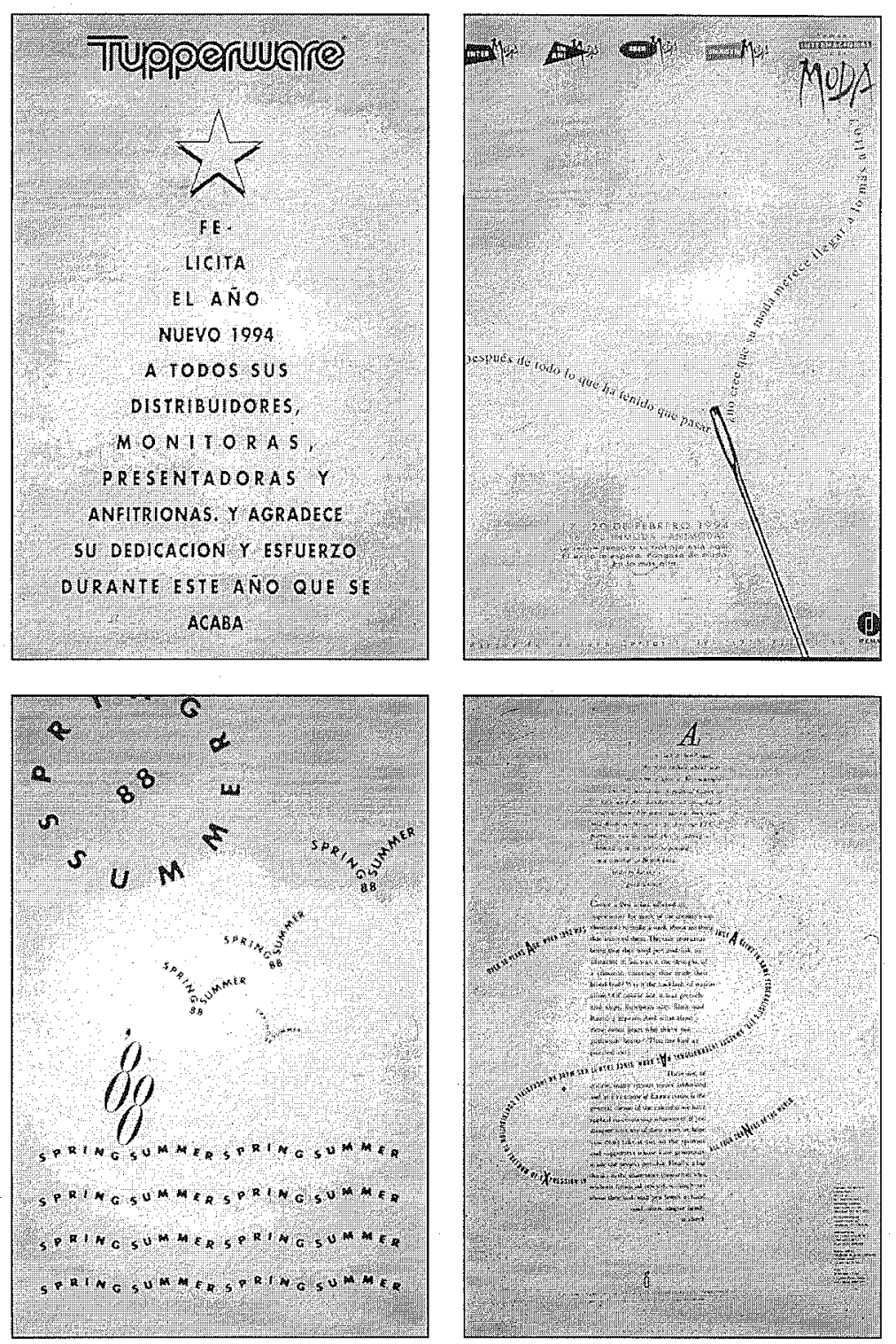

Figura 8 